\title{
Autism as a neurodevelopmental disorder of mind-reading
}

\author{
Joint British Academy-British Psychological Society Lecture \\ read 23 September 2014
}

\section{FRANCESCA HAPPÉ}

Fellow of the Academy

Abstract: The everyday ability to track what others are thinking, so-called 'theory of mind', has been the subject of hundreds of studies in typically developing ('neurotypical') children and clinical groups, most notably autism. The social and communication deficits that define autism can be understood as direct signs of difficulties in theory of mind; failure to recognise communicative intentions and difficulty connecting with another's interests or viewpoints. Much less consideration has been given to the developmental or downstream consequences of theory of mind. Here I will argue that theory of mind is a gatekeeper in neurotypical development, opening the way for a range of sophisticated abilities, and facilitating learning of new skills and information through social 'osmosis'. In autism, where spontaneous theory of mind fails to develop, we can track downstream consequences; what happens when the gatekeeper function fails. Interestingly, since gatekeepers keep things out, as well as let things in, some of the consequences of failure of intuitive and obligatory theory of mind in autism, may be positive.

Keywords: 'theory of mind', autism, neurotypical development, social, communication.

\section{YOUNG CHILDREN 'READ MINDS’}

Aged two and a half, our daughter Poppy delightedly exclaimed: 'Grandma thought Mr Moon was Daddy!', when her grandmother opened the door expecting one person and finding, to her surprise, a different and unexpected visitor. This memory has stuck with me because it was a spontaneous demonstration of 'theory of mind' (ToM); the attribution of mental states to explain (or predict) behaviour. Like the now-classic Sally-Anne false-belief test (see Figure 1), this example shows that Poppy could track 


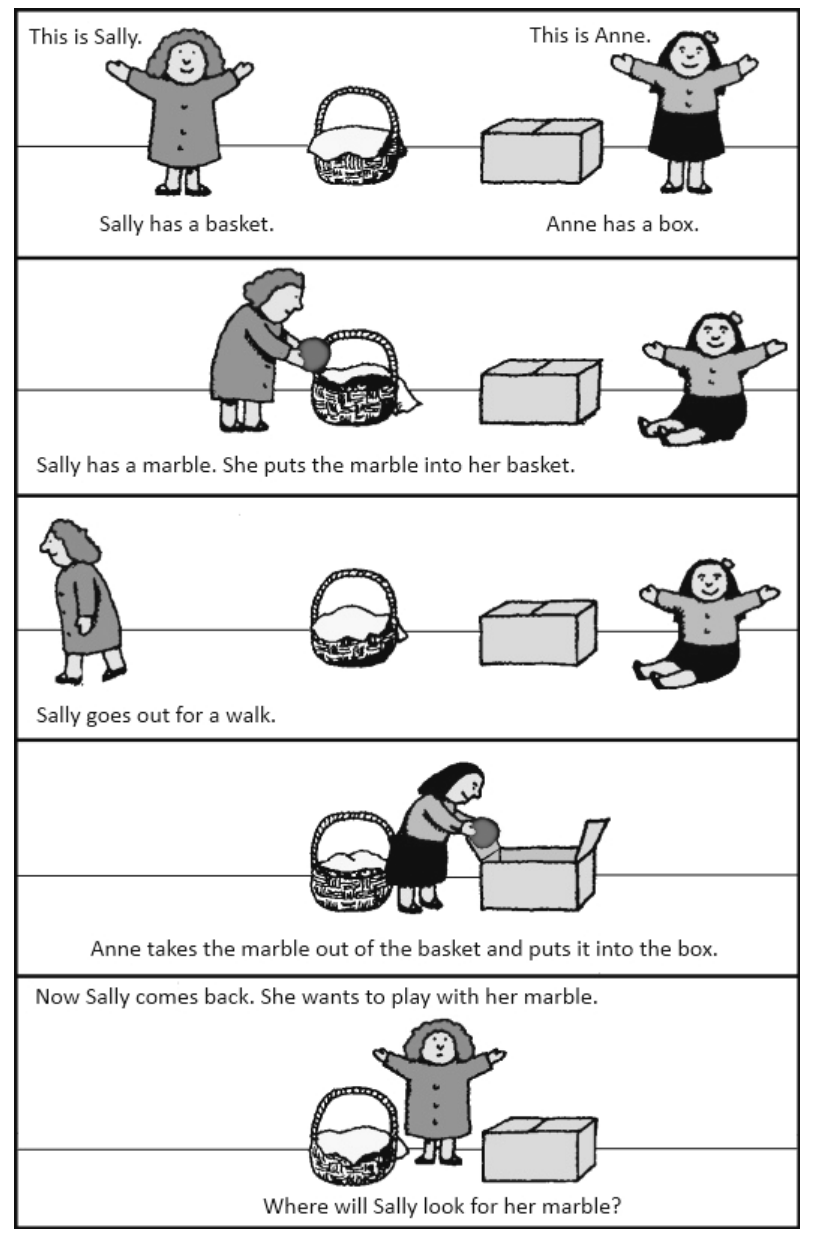

Figure 1: The Sally-Anne test of the ability to attribute a false belief. (Source: from Frith 1989, with grateful thanks.)

what her grandmother thought, even when that thought was mistaken or different from her own.

Although formal and explicit tests like the Sally-Anne task are typically passed at age three or four years, Poppy is probably not a social savant; implicit ToM tests (using habituation or anticipatory looking measures) suggest children as young as 15 months may track a character's mistaken belief (for review see, e.g., Sodian 2011; but see Heyes 2014, for debate). Indeed, naturalistic studies of toddler interaction and mental-state talk suggest a rich appreciation of other minds. Failure on explicit ToM tests may reflect additional task demands (notably in executive functions such as inhibition), and a natural default to attribute true beliefs. 
My argument in this paper will be that this early emerging 'mind-reading' ability acts as a gatekeeper in development, opening the doors to a range of important abilities. The downstream effects of mind-reading are thrown into contrast by examining developmental effects of the absence of spontaneous ToM in individuals with autism.

\section{AUTISM: IS IT A NEURODEVELOPMENTAL DISORDER OF MIND-READING?}

Autism spectrum disorder (ASD) is a neurodevelopmental condition diagnosed on the basis of social and communication impairments plus restricted and repetitive interests and activities. It is 30 years since Uta Frith, Alan Leslie and Simon BaronCohen demonstrated that children with ASD tended to fail ToM tests like the SallyAnne false-belief task, in contrast to typically developing children or those with Downs Syndrome of the same mental age (Baron-Cohen et al. 1985). The ToM account of ASD has not gone unchallenged; some people with ASD pass ToM tasks, suggesting ToM impairment is not universal in ASD. However, measures of spontaneous looking behaviour suggest that implicit and automatic ToM is still impaired even when correct verbal answers are given to the explicit false-belief question (Senju 2013). Indeed, people with ASD often say that working out a social situation feels for them akin to doing complex mental arithmetic; slow, conscious calculation that is both taxing and laborious. There is also debate concerning the primacy of ToM deficits in ASD, which some hypothesise to be secondary to, for example, social motivation deficits (e.g. Carré et al. 2015). Interestingly, such accounts predicted that early emerging abnormalities in social looking and smiling in infants with ASD would precede the much later emergence of ToM in typical development or its impairment in ASD. However, recent prospective studies of the infant siblings of children with ASD (who are at higher genetic risk of ASD) have not supported these predictions. Indeed, results to date suggest that differences in social response before 12 months old do not reliably distinguish infants who will later be diagnosed with ASD (Ozonoff $e t$ al. 2010). Lastly, the specificity of ToM deficits has been challenged; individual with intellectual impairment (without ASD) and children born deaf in hearing families (i.e., not exposed to sign as a first language), often fail ToM tasks. It should be noted, however, that these groups do not show prominent social impairments, and it therefore seems likely that ToM task failure reflects difficulties with other aspects of the tests. San José Cáceres et al. (2014) showed, for example, that testing ToM nonverbally with a simple penny-hiding game revealed much better performance in intellectually impaired children than in those with ASD. 
The notion that ASD is at heart characterised by impaired mind-reading has been useful precisely because it makes sense of the particular pattern of social and communication difficulties seen in this heterogeneous group. For example, problems attributing speaker's intentions can explain the range of communication impairments in ASD. Absence of any communication makes sense without ToM; why communicate if you do not recognise that there are minds to contact, different thoughts in different heads to be transmitted and shared? Grammatically correct but pragmatically impaired communication also makes sense without ToM; ordinary phrases like 'Paint the child next to you' or 'We'll go swimming in the minibus' are open to puzzling over-literal interpretation if you do not recognise the speaker's intention. Difficulty recognising (second-order) intentions also explains problems distinguishing jokes from lies from sarcasm.

The ToM account has been useful in providing a way for teachers, parents and clinicians to understand the mismatch between ASD and 'neurotypical' ways of processing the world. It has also opened the possibility for neuroimaging investigation of the neural substrates of ToM in neurotypicals and possible differences in ASD (for review, see, e.g., Koster-Hale \& Saxe 2013). The ToM account informed the search for early markers of ASD, focusing attention, for example, on reduced or absent pretend play (hypothesised to require attribution of mental states) as a sign of ASD in the second year of life (Dumont-Mathieu \& Fein 2005). It has also suggested new types of intervention, with many efforts to teach ToM or a circumventing strategy to allow calculation of mental states (debatably with limited success; Fletcher-Watson et al. 2014).

It should be recognised, of course, that differences in ToM are not all there is to ASD. The defining symptoms of rigid and repetitive activity and interests are not well explained by ToM deficits, and elsewhere I have suggested that ASD may be better conceptualized as a compound of different and 'fractionable' cognitive characteristics (Happé et al. 2006; Brunsdon \& Happé, 2014), including differences (rather than deficits) in cognitive style that predispose to talent in areas where detail-focus is advantageous (Happé \& Vital 2009). These other aspects of ASD, and recent theories proposing a single explanation for social and nonsocial features (e.g. Markram \& Markram, 2010), are beyond the scope of the present paper.

While there are hundreds of research articles on testing ToM in individuals with ASD, there are rather few considering the long-term, developmental or downstream effects of 'mind-blindness'. In this paper I would like to consider effects in three areas, before reflecting on possible limitations for typically developing children caused by obligatory mind-reading. 


\section{THEORY OF MIND AS A 'GATEKEEPER'}

I want to suggest that the recognition and representation of others' mental states open the gates to social learning - both the learning of social information and the learning of non-social content via social routes. Much of this might pass without notice, were it not that children with ASD do not readily represent the mental states of others and hence follow a very different learning trajectory. Here I want to discuss briefly three downstream effects of the lack of intuitive ToM; on word learning, intelligence and self-awareness.

\section{Learning Words}

Work by Bloom and others has amply demonstrated the social sophistication underlying early language acquisition (Bloom 2000; Brosseau-Liard et al. 2015). To learn words and their meanings, toddlers track a speaker's intention by checking eye gaze, pointing and so forth. They do not simply attach a new word overheard to an unlabelled object that is their current focus of attention. If they did-instead of inferring the speaker's intended referent-frequent mis-mappings might be expected.

Children with ASD, by contrast, would not be expected to recognise the act of ostension that is pointing and naming, nor would they readily attribute the appropriate intention to the speaker. Experimental studies suggest that children with autism do not look to speakers for clues to the intended referent during word learning paradigms in the laboratory (Baron-Cohen et al. 1997). Instead, they may take the novel label to apply to the object of their (versus the speaker's) attention, leading to mismappings. This may explain classic examples of 'irrelevant and metaphorical language' described as early as 1946 by Leo Kanner; words or utterances with no apparent communicative meaning in the current situation may be associated with past objects or events (e.g. a girl with autism who repeated, 'Dogs don't cry', when upset; a boy who said 'Peter-eater' when he saw saucepans, after experiencing pans clattering to the ground while his mother recited the 'Peter, Peter, pumpkin-eater' nursery rhyme).

Approximately 20 per cent of children with ASD do not have functional spoken language, and for the remaining 80 per cent, the ToM deficit account would suggest that words are learnt in a fundamentally different way from in typical development. To find out more about how word learning proceeds without ToM 'opening the gate', we are currently collecting information from the parents of children with ASD, neurotypical development or developmental delay. We constructed a parent survey with questions relevant to mis-mappings that might occur if associations are formed undirected by tracking a speaker's intended referent. To date, we have survey data 
from parents of 61 children with ASD and 76 neurotypical children; we are also collecting data from parents of developmentally delayed children, matched to the ASD group for estimated verbal ability, but the number is as yet too small to report.

Parents of children with ASD reported late speech (mean age 32 months for first words other than mamma/dadda, versus 17 months in the typically developing group), as has been frequently reported. More interestingly, 31 per cent of the parents of ASD children were surprised by their first words, compared with 7 per cent in the neurotypical group. Examples of unusual first words included 'money', and whole phrases such as 'over the bridge', or 'snip snip went the scissors'. More than half (54 per cent) the parents of children with ASD said their child got and then lost words (versus 1 per cent in the neurotypical group), so that a word might be said for some days or weeks and then never heard again. Over half the parents (52 per cent) said their child with ASD spoke words she or he did not appear to understand when the parents spoke them (versus 11 per cent in the neurotypical group). Like Kanner's early cases, 69 per cent of the ASD children were reported by their parents to use words idiosyncratically (versus 18 per cent of typically developing children), notable examples being a child who said 'beer' to mean video, and another who said 'next week' to refer to ice cream. These idiosyncratic errors found in the ASD group suggest a different route to language learning. We may hypothesise that, in the absence of ToM, mis-mappings are made when novel labels are associated with objects or situations for which the child has no term. Whether these associations are made in a single instance remains unclear. Perhaps the loss of words once used reflects failure of one-off associations to stand up to implicit statistical learning over time, which is suggested to be intact in ASD (Foti et al. 2015). Indeed, it must be acknowledged that, despite these idiosyncrasies, most children with ASD do learn language (albeit with delay), establishing a vocabulary that is apparently not unlike that of their non-ASD peers (Boucher 2012; Haebig et al. 2015). In our survey data so far, most parents said their ASD children recognised letters and many read with little delay; learning to decode written language may rely far less on understanding ostension and tracking speaker's intention than does spoken word learning. It will be important to establish whether children with ASD, in the absence of the gatekeeper ToM, learn the agreed meanings of words in a different way, as this could inform intervention efforts.

\section{Does IQ Measure the Footprint of ToM?}

ToM may be a gatekeeper not only to the effortless learning of agreed labels for things, but also to the acquisition of knowledge and skills through 'social osmosis'. Kristina Scheuffgen, Uta Frith, Mike Anderson and I explored whether knowledge and skills 
as measured by conventional IQ tests lagged behind capacity to learn, as assessed by the inspection time task. Inspection time (duration of exposure needed to make a very simple perceptual judgement) reflects efficiency of processing and correlates well with measured IQ in typically developing and intellectually impaired (non-ASD) samples. Scheuffgen et al. (2000) found that a group of ASD children had inspection times as fast as those of typically developing children with mean IQ 30 points higher (mean full IQ 83 versus 118, respectively). In other words, measured IQ was lower than expected from inspection time in ASD, but not in intellectually impaired children. We hypothesise that this discrepancy reflects the difficulty of acquiring information through social routes in ASD. More recently, Greg Wallace showed that inspection time and IQ did not correlate significantly in ASD, compared with non-ASD samples (Wallace et al. 2009). Antonia San José Cáceres also replicated the discrepancy between IQ and inspection time in a lower functioning group with ASD or intellectual impairment (mean verbal IQ 52 in both groups), again finding inspection times were much faster than expected in the ASD group (San José Cáceres 2012). These findings may suggest that we could unlock good learning potential in some people with ASD by giving non-social routes to acquiring information and skills. As Ros Blackburn, who speaks so powerfully about her own experience of having ASD, says: 'It's the things you neurotypical are never taught but just 'know' that I don't get' (personal communication). A good example is the young man with ASD who, having been encouraged to buy some deodorant for when he felt hot and sweaty, proceeded to spray it on his face. Neurotypicals are not taught in school where to spray deodorant, but we somehow know it merely from being around others; for people with ASD this social osmosis may not occur spontaneously because of impaired ToM.

\section{Does Mind-blindness Extend to Own Mind?}

A large body of work suggests that attributing mental states to others may be nonintuitive for people with ASD. An interesting question is whether self-awareness is affected by differences or difficulties in meta-representation. Elsewhere, Dave Williams and I have reported data from studies of self-awareness in ASD (e.g., Williams \& Happé 2010). These suggest that, for example, reporting one's own past false belief is difficult for children with ASD, unless they can use memory of a past utterance to stand in for memory of a prior (false) belief (Williams \& Happé 2009). Children with ASD also struggled to recognise that a reflex action was not deliberate, or that a surprise outcome of their action was not what they intended. These findings suggest that, for at least some people with ASD, the ability to reflect on their own thoughts as thoughts may be somewhat different from the neurotypical experience. 
It is intriguing to consider the downstream effects of problems in 'reading own mind'. Might difficulty reflecting on one's own thoughts contribute to 'executive dysfunction' in ASD; the well-documented problems in planning, shifting set and monitoring performance, which make people with ASD so challenged by change and novelty? Difficulty reflecting on own thoughts might limit mental rehearsal of possible events, or imaginative planning of alternative courses of action. ToM and executive function performance show a significant relationship in both ASD and typical development (see, e.g., Brunsdon \& Happé 2013; Devine \& Hughes 2014), and various explanations have been proposed including task demands in both directions; many ToM tests require inhibitory control, and some executive tests implicitly tap the ability to infer the tester's intention (White 2013). A developmental effect of impaired self-awareness on reflective executive functions provides an additional possible reason for correlations between ToM and executive function.

Differences in self-awareness might also impact emotional well-being. Of course, people with ASD have complex ideas and strong emotions, but differences in how they reflect on or re-represent those states might result in emotional confusion, or difficulty in controlling emotions. If so, external scaffolds for reflecting on inner states, such as diaries, sketches and night-time monologues, might be especially important for people with ASD.

\section{GATEKEEPERS ALSO KEEP THINGS OUT: OBLIGATORY SOCIAL INTUITION HAS COSTS}

It is remarkable that typically developing children readily track others' mental states from such an early age. Does this reflect an evolved preparedness to form the meta-representations that allow us to capture not merely the real state of affairs (the ball is in the box), but a person's propositional attitude towards that state of affairs (Mary doesn't know 'the ball is in the box')? This is the subject of considerable debate. However, I would like to suggest that ToM shares at least one property with evolved or developed cognitive 'modules': attributing mental states may be obligatory, in the presence of relevant trigger stimuli. By analogy, reading is an acquired modular skill that cannot be turned off at whim; if we see a familiar word in our language we cannot help but extract its meaning and sound; we cannot choose to see it as a sequence of meaningless squiggles. In the same way, we cannot resist seeing intention in acts of ostension; it is almost impossible to pass a group pointing and staring at the sky without looking up too. Might obligatory ToM have some disadvantages for typically developing children, disadvantages that ASD individuals are spared? 
Obligatory ToM may make it hard for us to resist the thoughts, beliefs, values and preferences of others, or to stay 'true to ourselves' within the human herd. Conformity starts surprisingly early in typical development. Pre-schoolers prefer to take information from 'non-dissenters' rather than from dissenters (Corriveau \& Harris 2010), and four-year-olds change their answers in public (but not in private) to match the majority view, even when this is patently wrong (Haun \& Tomasello 2011).

A simple experiment by Shutts et al. (2010) demonstrates this conformity effect. Three-year-olds were asked to choose between two novel (made-up) toys, clothes, foods or games - one endorsed by a same-sex peer (e.g., 'My name is Jordan. I love playing Kazoop. Kazoop is my favourite thing to play.'), the other by an opposite-sex peer. Children chose the toy, food, game or clothes endorsed by the same-sex peer. Rather depressingly, when asked why they had chosen that toy, the children in the study did not refer to the endorser or his or her gender, but simply claimed to like that one better or referred to the object's properties; they had no idea where their bias had really come from.

This conformity and need to belong are powerful throughout childhood and into adolescence. Over and Carpenter (2009) found that five-year-olds primed with videos in which one shape was ostracised by a group of shapes, imitated the actions of a model more closely than children in a control condition. In adolescents, anxiety (specifically fear of negative evaluation) is associated with greater social conformity and memory suggestibility (Wright et al. 2010). Being, as neurotypicals are, 'social savants' has costs as well as benefits.

A beautiful study by Bonawitz et al. (2012) illustrates the potential costs of automatic attribution of intentions. The authors studied the trade-off between instruction and exploration in typically developing pre-schoolers. They showed that children were less likely to discover all the hidden functions of a novel toy if a single function had been demonstrated by a knowledgeable teacher, versus an adult who claimed to have found the toy, or an adult apparently interrupted after demonstrating a single function. It appears that the typically developing three-year-olds and four-year-olds inferred that the knowledgeable adult demonstrated what was relevant, and all that was relevant - and therefore ceased their own exploration sooner. In Bonawitz et al.'s words, neurotypical children 'draw rational (if fallible) inferences about the absence of information that is not instructed.'

A clear prediction is that children with ASD would not be sensitive to the apparent knowledge of the adult, and would therefore discover more functions than the typically developing children in the key condition (where a knowledgeable instructor demonstrates a single function). Thus, in certain circumstances, not attributing intentions to others may be beneficial. Bonawitz et al. point out that ' $\ldots$ costs and 
benefits of instruction depend on how knowledgeable and helpful the teacher is, and on how likely the learner is to discover either the target information or novel information on her own. The inductive bias by which teaching constrains the learner's hypothesis space cuts both ways.' In areas of knowledge where previous learners or authoritative teachers have discovered most of the relevant information, instruction is hugely time-saving, but in more open-ended domains or where we do not know how much more there is to discover, the trade-off with exploration may be more costly. Perhaps people with ASD/high-ASD traits have contributed so much to science because it is just such a domain? Elsewhere we have speculated that the resistance to others' ideas may contribute to originality of thought in ASD, and indirectly to the talents that are found in perhaps a third of those with ASD (Happé \& Vital 2008).

\section{CONCLUSIONS}

Social and communication difficulties in ASD may be a direct result of lack of automatic and intuitive attribution of mental states. Here I have argued that the learning environment for children with ASD is fundamentally altered by lack of intuitive ToM, with clear downstream consequences. Understanding these is of direct relevance for helping people with ASD to achieve their full potential, by giving alternative ways to access information and to develop skills that are socially mediated in neurotypicals. Such research and intervention efforts will not only benefit those with ASD, they may also teach us about the limitations imposed on neurotypical learning by our obligatory mind-reading.

\section{REFERENCES}

Baron-Cohen, S., Baldwin, D. A. \& Crowson, M. (1997), 'Do Children with Autism Use the Speaker's Direction of Gaze Strategy to Crack the Code of Language?', Child Development, 68: 48-57. http://dx.doi.org/10.2307/1131924

Baron-Cohen, S., Leslie, A.M. \& Frith, U. (1985), 'Does the Autistic Child Have a "Theory of Mind”?', Cognition, 21(1): 37-46. http://dx.doi.org/10.1016/0010-0277(85)90022-8

Bloom, P. (2000), How Children Learn the Meanings of Words (Cambridge, MA: MIT Press).

Bonawitz, E., Shafto, P., Gweon, H., Goodman, N. D., Spelke, E. \& Schulz, L. (2011), 'The DoubleEdged Sword of Pedagogy: Instruction Limits Spontaneous Exploration and Discovery', Cognition, 120: 322-30. http://dx.doi.org/10.1016/j.cognition.2010.10.001

Boucher, J. (2012), 'Research Review: Structural Language in Autistic Spectrum Disorder-characteristics and causes', Journal of Child Psychology and Psychiatry, 53: 219-33. http://dx.doi.org/10.1111/j.1469-7610.2011.02508.x

Brosseau-Liard, P., Penney, D. \& Poulin-Dubois, D. (2015), 'Theory of Mind Selectively Predicts Preschoolers' Knowledge-Based Selective Word Learning', British Journal of Developmental Psychology, 33: 464-75. http://dx.doi.org/10.1111/bjdp.12107 
Brunsdon, V. \& Happé, F. (2014), 'Exploring the 'Fractionation' of Autism at the Cognitive Level', Autism: The International Journal of Research and Practice, 18: 17-30. http://dx.doi.org/10.1177/1362361313499456

Carré, A., Chevallier, C., Robel, L., Barry, C., Maria, A. S., Pouga, L., Philippe, A., Pinabel, F. \& Berthoz, S. (2015), 'Tracking Social Motivation Systems Deficits: The Affective Neuroscience View of Autism', Journal of Autism and Developmental Disorders, 45: 3351-63. http://dx.doi.org/10.1007/s10803-015-2498-2

Corriveau, K. \& Harris, P. L. (2010), 'Young Children's Trust in What Other People Say', in K.J. Rotenberg (ed.), Interpersonal Trust during Childhood and Adolescence (Cambridge: Cambridge University Press) 87-109. http://dx.doi.org/10.1017/CBO9780511750946.005

Devine, R. T. \& Hughes, C. (2014), 'Relations Between False Belief Understanding and Executive Function in Early Childhood: A Meta-Analysis', Child Development, 85: 1777-94. http://dx.doi.org/10.1111/cdev.12237

Dumont-Mathieu, T. \& Fein, D. (2005), 'Screening for Autism in Young Children: The Modified Checklist for Autism in Toddlers (M-CHAT) and Other Measures', Mental Retardation and Developmental Disabilities Research Reviews, 11: 253-62. http://dx.doi.org/10.1002/mrdd.20072

Fletcher-Watson, S., McConnell, F., Manola, E. \& McConachie, H. (2014), 'Interventions Based on the Theory of Mind Cognitive Model for Autism Spectrum Disorder (ASD)', Cochrane Database Systematic Reviews, Issue 3.

Foti, F., De Crescenzo, F., Vivanti, G., Menghini, D. \& Vicari, S. (2015), 'Implicit Learning in Individuals with Autism Spectrum Disorders: A Meta-Analysis', Psychological Medicine, 45: 897-910. http://dx.doi.org/10.1017/S0033291714001950

Frith, U. (1989), Autism: Explaining the Enigma (Oxford: Blackwell)

Haebig, E., Kaushanskaya, M. \& Weismer, S. E. (2015), 'Lexical Processing in School-Age Children with Autism Spectrum Disorder and Children with Specific Language Impairment: The Role of Semantics',Journal of Autism and Developmental Disorders. http://dx.doi.org/10.1007/s10803-015-2534-2

Happé, F. \& Vital, P. (2009), 'What Aspects of Autism Predispose to Talent?', Philosophical Transactions of the Royal Society of London-Series B: Biological Sciences, 364: 1369-75. http://dx.doi.org/10.1098/rstb.2008.0332

Happé, F., Ronald, A. \& Plomin, R. (2006), 'Time to Give up on a Single Explanation for Autism', Nature Neuroscience. 9: 1218-20. http://dx.doi.org/10.1038/nn1770

Haun, D. \& Tomasello, M. (2011), 'Conformity to Peer Pressure in Preschool Children', Child Development, 82: 1759-67. http://dx.doi.org/10.1111/j.1467-8624.2011.01666.x

Heyes, C. (2014), 'False Belief in Infancy: A Fresh Look', Developmental Science, 17: 647-59. http://dx.doi.org/10.1111/desc. 12148

Kanner, L. (1946), 'Irrelevant and Metaphorical Language in Early Infantile Autism', American Journal of Psychiatry 103: 242-6 http://dx.doi.org/10.1176/ajp.103.2.242

Koster-Hale, J. \& Saxe, R. (2013), 'Functional Neuroimaging of Theory of Mind', in, S. Baron-Cohen, M. Lombardo, H Tager-Flusberg \& D. Cohen (eds). Understanding Other Minds: Perspectives from Developmental Social Neuroscience (Oxford: Oxford University Press) 132-63 http://dx.doi.org/10.1093/acprof:oso/9780199692972.003.0009

Markram, K. \& Markram, H. (2010), 'The Intense World Theory-A Unifying Theory of the Neurobiology of Autism. Frontiers in Human Neuroscience, 4: 224. http://dx.doi.org/10.3389/fnhum.2010.00224

Over, H. \& Carpenter, M. (2009), 'Priming Third-Party Ostracism Increases Affiliative Imitation in Children', Developmental Science, 12(3): F1-F8. http://dx.doi.org/10.1111/j.1467-7687.2008.00820.x 
Ozonoff, S., Iosif, A.M., Baguio, F., Cook, I.C., Hill, M.M., Hutman, T. \& Young, G.S. (2010), 'A Prospective Study of the Emergence of Early Behavioral Signs of Autism', Journal of the American Academy of Child and Adolescent Psychiatry, 49: e251-e252.

San José Cáceres, A. (2012), 'Information Processing, Intelligence and Social Learning in Autism Spectrum Disorder', unpublished PhD thesis, King's College London.

San José Cáceres, A., Keren, N., Booth, R. \& Happé, F. (2014), 'Assessing Theory of Mind Nonverbally in those with Intellectual Disability and ASD: The Penny Hiding Game', Autism Research, 7: 608-16. http://dx.doi.org/10.1002/aur.1405

Scheuffgen, K., Happé, F., Anderson, M. \& Frith, U. (2000), 'High “Intelligence”, Low "IQ”? Speed of Processing and Measured IQ in Children with Autism', Development and Psychopathology, 12: 83-90. http://dx.doi.org/10.1017/S095457940000105X

Senju, A. (2013), 'Atypical Development of Spontaneous Social Cognition in Autism Spectrum Disorders', Brain and Development, 35: 96-101. http://dx.doi.org/10.1016/j.braindev.2012.08.002

Shutts, K., Banaji, M. R. \& Spelke, E. S. (2010), 'Social Categories Guide Young Children's Preferences for Novel Objects', Developmental Science, 13: 599-610. http://dx.doi.org/10.1111/j.1467-7687.2009.00913.x

Sodian, B. (2011), 'Theory of Mind in Infancy', Child Development Perspectives, 5(1): 39-43. http://dx.doi.org/10.1111/j.1750-8606.2010.00152.x

Wallace, G.L., Anderson, M. \& Happé, F. (2009), 'Brief Report: Information Processing Speed is Intact in Autism but not Correlated with Measured Intelligence', Journal of Autism and Developmental Disorders, 39: 809-14. http://dx.doi.org/10.1007/s10803-008-0684-1

White, S.J. (2013), 'The Triple I Hypothesis: Taking Another('s) Perspective on Executive Dysfunction in Autism', Journal of Autism and Developmental Disorders, 43(1): 114-21. http://dx.doi.org/10.1007/s10803-012-1550-8

Williams, D.M. \& Happé, F. (2009), 'What Did I Say? Versus What Did I Think? Attributing False Beliefs to Self amongst Children With and Without Autism', Journal of Autism and Developmental Disorders, 39: 865-73. http://dx.doi.org/10.1007/s10803-009-0695-6

Williams, D. \& Happé, F. (2010), 'Representing Intentions in Self and Other: Studies of Autism and Typical Development', Developmental Science, 13: 307-19. http://dx.doi.org/10.1111/j.1467-7687.2009.00885.x

Wright, D. B., London, K. \& Waechter, M. (2010), 'Social Anxiety Moderates Memory Conformity in Adolescents', Applied Cognitive Psychology, 24: 1034-45. http://dx.doi.org/10.1002/acp.1604

Note on the author: Francesca Happé is Professor of Cognitive Neuroscience and Director of the MRC Social, Genetic \& Developmental Psychiatry Centre at the Institute of Psychiatry, Psychology \& Neuroscience, King's College London. Her research focuses on autism spectrum conditions. She has explored the nature of social understanding in typical development and 'mind-reading' difficulties in autism. She is also actively engaged in studies of abilities and assets in people with autism, and their relation to detail-focused cognitive style. As well as cognitive methods, her research has involved functional imaging studies, exploration of acquired brain lesions, and behaviour genetic methods. She has received the British Psychological Society Spearman Medal, the Experimental Psychology Society Prize and the Royal Society Rosalind Franklin Award, and was made a Fellow of the British Academy in 2014. 
Other work by the same author:

Brunsdon, V.E.A., Colvert, E., Ames, C., Garnett, T., Gillan, N., Hallett, V., Lietz, S., Woodhouse, E., Bolton, P. \& Happé, F. (2015), 'Exploring the Cognitive Features in Children With Autism Spectrum Disorders, Their Co-Twins, and Typically-Developing Children Within a PopulationBased Sample', Journal of Child Psychology and Psychiatry, 56: 893-902

Happé, F (1994), Autism: An Introduction to Psychological Theory (London: Psychology Press); (1995) (Cambridge, MA: Harvard University Press).

Happé, F. \& Frith, U. (2014), 'Annual Research Review: Towards a Developmental Neuroscience of Atypical Social Cognition', Journal of Child Psychology and Psychiatry, 55: 553-77.

http://dx.doi.org/10.1111/jcpp.12162

francesca.happe@kcl.ac.uk

To cite the article: Francesca Happé (2015), 'Autism as a neurodevelopmental disorder of mind-reading', Journal of the British Academy, 3: 197-209.

DOI $10.85871 / \mathrm{jba} / 003.197$

This article is licensed under a

Creative Commons Attribution-NonCommercial-NoDerivs 3.0 Unported License.

Journal of the British Academy (ISSN 2052-7217) is published by

The British Academy - the national academy for the humanities and social sciences.

10-11 Carlton House Terrace, London, SW1Y 5AH

www.britishacademy.ac.uk 